\title{
Evolution of Aromatic and Furanic Congeners in the Maturation of Cider Brandy: A Contribution to Its Characterization
}

\author{
J uan Mangas, ${ }^{\dagger}$ Roberto Rodríguez, ${ }^{\dagger}$ J avier Moreno, ${ }^{\dagger}$ Belén Suárez, ${ }^{\dagger}$ and Domingo Blanco*,, \\ Centro de Investigación Aplicada y Tecnología Agroalimentaria, Apartado 13, \\ E-33300 Villaviciosa Asturias, Spain, and Departamento de Química F ísica y Analítica, \\ Universidad de Oviedo, E-33006 Oviedo, Spain
}

\begin{abstract}
A reliable HPLC method is described for determining aromatic and furanic congeners in cider brandies obtained from different kinds of cider (two technologies) and aged in American oak barrels. Except for 4-hydroxybenzaldehyde, the aging factor significantly influenced the concentration of benzoic acids, cinnamic acids, benzal dehydes, cinnamaldehydes, and furanoids, promoting an increase of these substances during aging; however, the technol ogy factor only influenced the furfural content, a higher level of this furanic compound being detected when cider obtained from apple juice concentrate is employed for the making of spirits. The application of cluster and factor analyses allowed the classification of the distillates on the basis of the raw material and aging time.
\end{abstract}

Keywords: Aromatic; furanic; cider brandy; HPLC

\section{INTRODUCTION}

After distillation of the cider, the brandy is stored in oak barrels in order to obtain certain harmonious sensorial characteristics. Throughout the maturation period, certain compounds are extracted from the wood. This is the case of hydrolyzable tannins and lignins as well as other low molecular mass phenolic compounds such as coumarins and certain phenolic acids (Miller et al., 1992). What is more, the hydroalcoholysis of the lignin causes the formation of benzoic and cinnamic aldehydes (Baldwin et al., 1967; Puech, 1984). The subsequent oxidation of said compounds gives rise to aromatic acids (Puech et al., 1977). These low molecular mass polyphenols have been considered appropriate indicators of the aging process of alcoholic beverages (Delgado et al., 1990). At the same time, the age of the barrel, the way it is used, and the charring process all control the level of furanic aldehydes in the spirits (Villalón et al., 1991; Puech et al., 1992).

The analysis of phenolic components of low molecular mass and furanic compounds was carried out by RPHPLC with UV detection (Lehtonen, 1983; Puech, 1988; Salagoïty-Auguste et al., 1987; Delgado et al., 1990; Villalón et al., 1991, 1992; Quesada et al., 1995), although a spectrofluorometer may be necessary for monitoring coumarins (Tricard et al., 1987). The aim of this work was to gain an insight into the development of the aromatic and furanic components in distillates of ciders during aging and to ascertain which of them can be employed for classifying spirits on the basis of raw material and aging time.

\section{MATERIALS AND METHODS}

Raw Material. Two types of cider were used to make spirits, cider produced by traditional technology (A) and cider obtained from apple juice concentrate (B). The traditionally elaborated cider was prepared from the juice of a mixture of

* Author to whom correspondence should be addressed.

† Centro de Investigación Aplicada y Tecnol ogía Agroalimentaria.

₹ Universidad de Oviedo. cider apples with different sensory properties endowing the resulting juice with an overall acidic nature. Said mixture was processed in a pilot plant which included the following steps: milling with a hammer mill and slow pressing with a batch mechanical press ( 4 days pressing time). The fermentation process was then carried out by wild microflora for 4 months. In the case of the type B cider, a starter of Saccharomyces cerevisiae was employed. The alcoholic degree was 6\% (v/v) for traditional cider and $8 \%(\mathrm{v} / \mathrm{v})$ for cider made from apple juice concentrate.

Distillation. The batch distillation system was employed for distilling each cider. The capacity of the copper wash-still distillation vessel was $500 \mathrm{~L}$, and steam was used as the heat source. The volatile compounds obtained in the first vessel of the still were transported to the rectifying column, which had 16 bubble-cap plates; 1150 and $1760 \mathrm{~L}$ of the traditional and type $B$ ciders, respectively, were employed to make the spirits. The alcoholic degree of the spirits was monitored during the distillation process. Three fractions of spirits, namely, heads, heart, and tails, were separated on the basis of their al coholic contents. The rejected distillation heads make up $1 \%(2.5 \mathrm{~L})$ of the total volume of distilled cider $(250 \mathrm{~L})$. The tails produced (average alcoholic degree $30 \%, v / v$ ) were reused in subsequent distillations. The alcohol content of the heart fraction was $65 \%$ $(\mathrm{v} / \mathrm{v})$ for the distillates obtained from traditional ciders and $62 \%$ for the distillates obtained from the ciders elaborated from apple juice concentrate. These heart fractions underwent an aging process in American oak barrels of $35 \mathrm{~L}$ capacity for 15 months. Samples were taken every 3 months in order to carry out the corresponding analytical determinations. The experiments for the aging of the spirits were performed in duplicate.

Sample Preparation. In order to increase the sensitivity of the analytical method and to eliminate most of the ethanol, the samples were subjected to a process of vacuum distillation at $30-35{ }^{\circ} \mathrm{C}$ and subsequently reconstituted in the mobile phase $A$ in such a way that the final concentration factor was 2. If most of the ethanol is not eliminated from the brandies, the elution strength of the sample is greater than that of the chromatographic mobile phase, and this fact leads to a split of the chromatographic peaks with a lower capacity factor, as is the case of 3,4,5-trihydroxybenzoic acid (gallic acid). However, approximately $40 \%$ of 2-furancarboxal dehyde (furfural) is lost with this operating procedure. Consequently, direct inyection of the sample without the preconcentration step is recommended for the determination of this compound.

Reagents. Standards of analytical quality were supplied by Fluka (Buchs, Switzerland), Merck (Darmstadt, Germany), and Sigma-Aldrich (Madrid, Spain); standard solutions were 
prepared in the same aqueous solution as described in the Sample Preparation section. The solvents employed were of HPLC quality and degassed with helium prior to use.

HPLC Analysis. A high-performance liquid chromatographic system (Waters Associates) equipped with a 712 automatic injector, M510 pumps, a Millenium v.2.0 software data module, and a 481 spectrophotometric detector was used. Separation of phenolic compounds was carried out in a Spherisorb ODS-2 column $(250 \mathrm{~mm} \times 4.6 \mathrm{~mm}, 3 \mu \mathrm{m})$ at $40{ }^{\circ} \mathrm{C}$ and detected at $280 \mathrm{~nm}$, using $2 \%$ acetic acid and $0.02 \mathrm{M}$ sodi um acetate (solvent $A$ ) and methanol (solvent $B$ ) as mobile phases. The elution conditions were as follows: starting $2.5 \%$ solvent $B$, isocratic for $4 \mathrm{~min}$, linear increase of solvent $B$ in solvent $A$ to $30 \% B$ for $16 \mathrm{~min}$, and isocratic for $25 \mathrm{~min}$, at a flow rate of $0.8 \mathrm{~mL} / \mathrm{min}$; samples were filtered through a 0.45 $\mu \mathrm{m}$ PVDF filter, and $10 \mu \mathrm{L}$ was injected into the HPLC system. The quantitation of polyphenols and furanic aldehydes was achieved by using the external standard method.

Statistical Analysis. Repeated measure analysis of variance with a Greenhouse-Geisser and Huynh-Feldt fitting was carried out using the SAS (1985) statistical package. Two factors were considered in this study, namely, technology (cider type) and aging (maturation in oak wood barrels). The data matrix was analyzed by principal components analysis and cluster analysis (SPSS, 1988). Multivariate analysis was carried out on 20 samples (spirits obtained from two technologies and with different aging) using 12 variables (aromatic and furanic compounds).

\section{RESULTS AND DISCUSSION}

Optimization of Chromatographic Analysis and Recovery Studies. Taking as a basis Lehtonen's (1983) work, we have optimized the separation of phenolic compounds of low molecular mass and furanic components in cider brandy. Different mobile phases, gradient profiles, and temperatures were tested; thus, when Lehtonen's chromatographic conditions ( $2 \%$ acetic acid and $0.02 \mathrm{M}$ sodium acetate as sol vent $\mathrm{A} ; 2 \%$ acetic acid, $0.02 \mathrm{M}$ sodium acetate, $14 \%$ methanol, and $2.5 \%$ 1-propanol as solvent B) were used for eluting analytes, a strong overlapping between 4-hydroxybenzal dehyde and an unknown peak was detected; this drawback could be overcome if solvent B is changed to $100 \%$ methanol, although complete resolution is not achieved. On the other hand, worse resolution was obtained between 4-hydroxy-3-methoxybenzoic acid (vanillic acid) and an unknown peak when the average $k^{\prime}$ value increased.

A temperature range of between 35 and $50{ }^{\circ} \mathrm{C}$ was tested in order to optimize the temperature; thus, a temperature lower than $35^{\circ} \mathrm{C}$ should not be considered due to the increase in the pressure drop across the column and the longer retention time of the analytes. The best conditions were obtained at $40^{\circ} \mathrm{C}$, since above this temperature strong overlapping between 3,4-dihydroxybenzoic acid (protocatechuic acid) and 5-(hydroxymethyl)-2-furancarboxaldehyde ((hydroxymethyl)furfural) was observed. A chromatogram of a cider brandy and a synthetic mixture of aromatic and furanic compounds is shown in Figure 1.

Recovery experiments were performed in order to demonstrate the accuracy of the analytical method. Known amounts of analytes (three spiking levels) were added to cider brandy samples, and the resulting spiked sample was subjected, in triplicate, to the entire anaIytical sequence. The contents of phenolic and furanic compounds in cider brandy and the recoveries of these substances added to it before the concentration step are shown in Table 1 . As we can see, recoveries ranged between $88 \%$ and $109 \%$ for all compounds tested. Repeatability of the proposed method was high, with
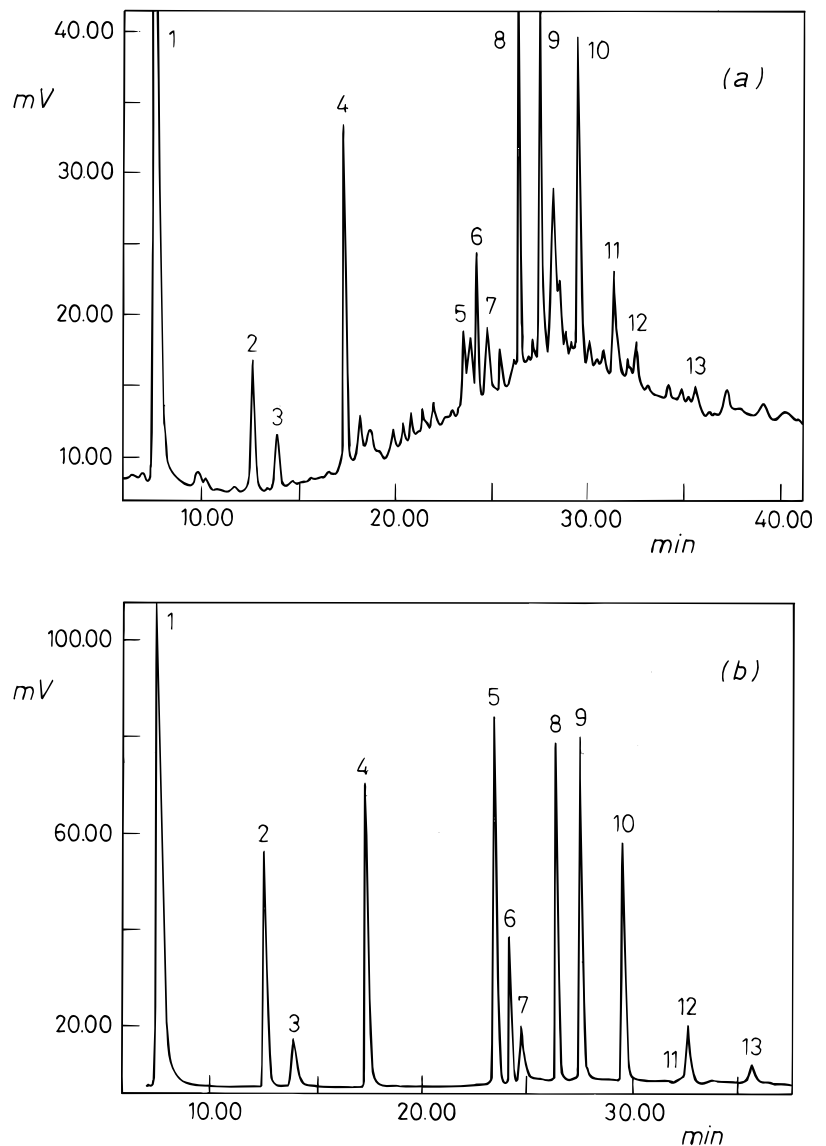

Figure 1. Chromatogram of a cider brandy (a) and a synthetic mixture (b): (1) 3,4,5-trihydroxybenzoic acid, (2) 5-(hydroxymethyl)-2-furancarboxal dehyde, (3) 3,4-dihydroxybenzoic acid, (4) 2-furancarboxal dehyde, (5) 4-hydroxybenzal dehyde, (6) 4-hydroxy-3-methoxybenzoic acid, (7) 3-(3,4-dihydroxyphenyl)2-propenoic acid, (8) 3,5-dimethoxy-4-hydroxybenzoic acid, (9) 4-hydroxy-3-methoxybenzal dehyde, (10) 3,5-dimethoxy-4-hydroxybenzaldehyde, (11) 7-hydroxy-6-methoxy-2H-1-benzopyran-2-one, (12) 3-(4-hydroxy-3-methoxyphenyl)-2-propenoic acid, and (13) 4-hydroxy-3-methoxycinnamal dehyde. The chromatographic conditions are described under Materials and Methods.

relative standard deviations usually less than $5 \%$. However, the determination of 2-furancarboxaldehyde under these conditions was not quantitative. In fact, a direct injection into the HPLC without the preconcentration step under vacuum should be considered in the analysis of this furanic component.

Evolution of Aromatic and Furanic Congeners during Aging of Cider Brandies. Different aromatic and furanic components were monitored throughout the aging of cider brandies, namely: benzoic acids $(3,4,5-$ trihydroxybenzoic acid, 3,4-dihydroxybenzoic acid, 4-hydroxy-3-methoxybenzoic acid, and 3,5-dimethoxy-4hydroxybenzoic acid (syringic acid)), cinnamic acids (3(3,4-di hydroxyphenyl)-2-propenoic acid (caffeic acid) and 3-(4-hydroxy-3-methoxyphenyl)-2-propenoic acid (ferulic acid)), benzoic aldehydes (4-hydroxy-3-methoxybenzaldehyde (vanillin), 4-hydroxybenzaldehyde, and 3,5dimethoxy-4-hydroxybenzaldehyde (syringaldehyde)), 4-hydroxy-3-methoxycinnamaldehyde (coniferylal dehyde), and furanoids (2-furancarboxaldehyde and 5-(hydroxymethyl)-2-furancarboxaldehyde).

3,4,5-Trihydroxybenzoic acid is a typical component of wood associated with the hydrolyzable tannins. Under the conditions of maturing of brandy, this acid is extracted from the wood, and furthermore, it is generally considered as an adequate aging indicator. 
Table 1. Recovery Studies of Aromatic and Furanoic Compounds Added to Distillates of Cider

\begin{tabular}{|c|c|c|c|c|}
\hline compound & $\begin{array}{c}\text { amount in spirit } \\
(\mathrm{mg} / \mathrm{L} \pm \mathrm{RSD})\end{array}$ & $\begin{array}{c}\text { amount } \\
\text { added (mg/L) }\end{array}$ & $\begin{array}{c}\text { found } \\
\text { (mg/L } \pm \text { RSD) }\end{array}$ & $\begin{array}{l}\text { recovery } \\
\text { (\%) }\end{array}$ \\
\hline 3,4,5-trihydroxybenzoic acid & $27.42 \pm 1.12$ & $\begin{array}{l}10.61 \\
21.21 \\
42.42\end{array}$ & $\begin{array}{l}38.32 \pm 3.39 \\
46.84 \pm 1.08 \\
65.81 \pm 2.34\end{array}$ & $\begin{array}{r}102.73 \\
91.56 \\
90.50\end{array}$ \\
\hline 5-(hydroxymethyl)-2-furancarboxal dehyde & $1.46 \pm 3.18$ & $\begin{array}{l}1.30 \\
2.59 \\
5.18\end{array}$ & $\begin{array}{l}2.75 \pm 3.08 \\
3.80 \pm 1.68 \\
6.18 \pm 2.22\end{array}$ & $\begin{array}{l}99.23 \\
90.35 \\
91.12\end{array}$ \\
\hline 3,4-dihydroxybenzoic acid & $3.07 \pm 4.14$ & $\begin{array}{l}1.61 \\
3.21 \\
6.42\end{array}$ & $\begin{array}{l}4.76 \pm 3.12 \\
6.16 \pm 3.05 \\
9.33 \pm 3.20\end{array}$ & $\begin{array}{r}104.97 \\
96.26 \\
97.51\end{array}$ \\
\hline 2-furancarboxaldehyde & $13.89 \pm 2.60$ & $\begin{array}{r}6.80 \\
13.60 \\
17.00\end{array}$ & $\begin{array}{l}20.97 \pm 0.23 \\
27.83 \pm 0.81 \\
31.12 \pm 0.56\end{array}$ & $\begin{array}{l}104.12 \\
102.50 \\
101.35\end{array}$ \\
\hline 4-hydroxybenzaldehyde & $0.49 \pm 2.53$ & $\begin{array}{l}1.46 \\
2.92 \\
5.83\end{array}$ & $\begin{array}{l}1.95 \pm 5.92 \\
3.40 \pm 3.13 \\
6.52 \pm 1.70\end{array}$ & $\begin{array}{r}100.00 \\
99.66 \\
103.43\end{array}$ \\
\hline 4-hydroxy-3-methoxybenzoic acid & $3.70 \pm 0.28$ & $\begin{array}{l}2.18 \\
4.35 \\
8.70\end{array}$ & $\begin{array}{r}6.08 \pm 1.24 \\
7.59 \pm 1.94 \\
11.40 \pm 2.39\end{array}$ & $\begin{array}{r}109.17 \\
89.43 \\
88.51\end{array}$ \\
\hline 3-(3,4-dihydroxyphenyl)-2-propenoic acid & $1.86 \pm 4.29$ & $\begin{array}{l}0.94 \\
1.88 \\
3.75\end{array}$ & $\begin{array}{l}2.89 \pm 2.41 \\
3.66 \pm 0.07 \\
5.56 \pm 2.40\end{array}$ & $\begin{array}{r}109.57 \\
95.74 \\
98.67\end{array}$ \\
\hline 3,5-dimethoxy-4-hydroxybenzoic acid & $5.82 \pm 4.33$ & $\begin{array}{r}2.86 \\
5.73 \\
11.45\end{array}$ & $\begin{array}{r}8.85 \pm 1.24 \\
10.98 \pm 4.04 \\
16.50 \pm 2.25\end{array}$ & $\begin{array}{r}105.94 \\
90.05 \\
93.28\end{array}$ \\
\hline 4-hydroxy-3-methoxybenzal dehyde & $5.06 \pm 5.79$ & $\begin{array}{r}2.62 \\
5.24 \\
10.48\end{array}$ & $\begin{aligned} 7.65 & \pm 2.97 \\
9.89 & \pm 3.45 \\
14.81 & \pm 2.26\end{aligned}$ & $\begin{array}{l}98.86 \\
92.18 \\
93.03\end{array}$ \\
\hline 3,5-dimethoxy-4-hydroxybenzal dehyde & $13.42 \pm 3.92$ & $\begin{array}{r}4.99 \\
9.99 \\
19.97\end{array}$ & $\begin{array}{l}18.84 \pm 3.26 \\
23.32 \pm 4.33 \\
32.91 \pm 3.13\end{array}$ & $\begin{array}{r}108.62 \\
99.10 \\
97.60\end{array}$ \\
\hline 7-hydroxy-6-methoxy-2H-1-benzopyran-2-one & $0.91 \pm 5.28$ & $\begin{array}{l}0.21 \\
0.41 \\
0.82\end{array}$ & $\begin{array}{l}1.13 \pm 7.58 \\
1.32 \pm 3.00 \\
1.70 \pm 8.92\end{array}$ & $\begin{array}{r}104.76 \\
100.00 \\
96.34\end{array}$ \\
\hline 3-(4-hydroxy-3-methoxyphenyl)-2-propenoic acid & $1.59 \pm 0.66$ & $\begin{array}{l}0.91 \\
1.81 \\
3.62\end{array}$ & $\begin{array}{l}2.52 \pm 5.14 \\
3.26 \pm 3.05 \\
4.87 \pm 1.14\end{array}$ & $\begin{array}{r}102.20 \\
92.27 \\
90.61\end{array}$ \\
\hline 4-hydroxy-3-methoxycinnamal dehyde & $0.82 \pm 6.65$ & $\begin{array}{l}0.64 \\
1.28 \\
2.56\end{array}$ & $\begin{array}{l}1.51 \pm 4.41 \\
1.99 \pm 1.88 \\
3.35 \pm 1.74\end{array}$ & $\begin{array}{r}107.81 \\
91.41 \\
98.83\end{array}$ \\
\hline
\end{tabular}

Under our experimental conditions, an increase $(\mathrm{P}<$ 0.01 ) in this component was detected during aging in all the cider brandies studied (Table 2), although significant differences were not found during the last step of aging (from 12 to 15 months). On the other hand, the technology factor did not influence the concentration of this benzoic acid.

In general, it is well established that benzoic acids, e.g., 4-hydroxy-3-methoxybenzoic acid and 3,5-dimethoxy4-hydroxybenzoic acid, result from cinnamic aldehydes, by means of a $\beta$-oxidation process, and the subsequent oxidation of the benzoic aldehydes formed. The concentration of both acids increased during aging $(P<0.01$ and $<0.05$, respectively) (Table 2); likewise, the concentration of 3,4-dihydroxybenzoic acid increased ( $P$ < 0.01 ) throughout the maturing. However, a decrease in the corresponding benzoic and cinnamic aldehydes was not found; on the contrary, the concentration of 4-hydroxy-3-methoxycinnamaldehyde increased $(P<$ 0.05 ) during aging. The same profile was observed for 4-hydroxy-3-methoxybenzal dehyde and 3,5-dimethoxy4-hydroxybenzaldehyde $(P<0.05)$. This fact might be explained on the basis of the more intensive lignin degradation in relation to the oxidation process of aldehydes, which promotes the accumulation of cinnamic alcohols and aldehydes. On the other hand, the aging factor did not influence the concentration of 4-hydroxybenzaldehyde.

The cinnamic acid 3-(3,4-dihydroxyphenyl)-2-propenoic accumulated $(P<0.01)$ during the maturing of the brandies (Table 2$)$. An interactive effect $(P<0.05)$ between both factors studied (technology and aging) was detected in the case of the 3-(3,4-dihydroxyphenyl)-2propenoic acid; thus, a higher level of this acid was obtained in the brandy made from type A cider, especially during the last step of maturing.

The 2-furancarboxaldehyde content was influenced by the technology factor $(P<0.05)$. As can be seen in Table 2 , the higher level of concentration was obtained with technology $\mathrm{B}$, which is due to the thermal treatment employed in the making of apple juice concentrate; moreover, the volatility of this component and its solubility in hydroalcoholic mixtures facilitate its re covery into the spirit when the cider is distilled. However, in the case of 5-(hydroxymethyl)-2-furancarboxaldehyde, no influence of the technology factor was found, in spite of the fact that this furanic compound is accumulated in the apple juice concentrate as a consequence of the Maillard reaction; the low volatility of this component prevents its recovery during the distillation process.

A significant influence of the aging factor was detected in both furanic components, $\mathrm{P}<0.01$ and $<0.05$ for 2-furancarboxaldehyde and 5-(hydroxymethyl)-2furancarboxaldehyde, respectively, which might be explained by taking into account the thermal treatment of wood barrels. As is well known, this technological treatment promotes the accumulation of furanic compounds in wood; these might be later extracted by the hydroal coholic mixture during the aging step.

Cluster Analysis. The information provided by cluster analysis is complementary to that given by factor 
Table 2. Average Content (mg/L) of Aromatic and Furanoic Compounds in Distillates of Cider

\begin{tabular}{|c|c|c|c|c|c|c|}
\hline \multirow[b]{2}{*}{ compound } & \multirow[b]{2}{*}{ spirit } & \multicolumn{5}{|c|}{ age (months) } \\
\hline & & 3 & 6 & 9 & 12 & 15 \\
\hline \multirow{2}{*}{ 3,4,5-trihydroxybenzoic acid } & A & 2.40 & 4.78 & 7.25 & 9.04 & 9.04 \\
\hline & $\mathrm{B}$ & 1.68 & 2.75 & 3.89 & 5.03 & 5.26 \\
\hline \multirow[t]{2}{*}{ 5-(hydroxymethyl)-2-furancarboxal dehyde } & A & 0.94 & 2.38 & 2.88 & 3.10 & 3.15 \\
\hline & B & 0.32 & 0.55 & 0.67 & 0.77 & 0.87 \\
\hline \multirow{2}{*}{ 3,4-dihydroxybenzoic acid } & A & 0.34 & 0.57 & 0.78 & 1.00 & 1.28 \\
\hline & $\mathrm{B}$ & 0.25 & 0.40 & 0.51 & 0.70 & 0.89 \\
\hline \multirow[t]{2}{*}{ 2-furancarboxaldehyde } & A & 2.37 & 3.79 & 4.44 & 5.58 & 5.50 \\
\hline & B & 14.88 & 14.71 & 14.87 & 15.12 & 15.87 \\
\hline \multirow[t]{2}{*}{ 4-hydroxybenzal dehyde } & A & 0.10 & 0.12 & 0.10 & 0.13 & 0.13 \\
\hline & $\mathrm{B}$ & 0.06 & 0.06 & 0.06 & 0.08 & 0.08 \\
\hline \multirow[t]{2}{*}{ 4-hydroxy-3-methoxybenzoic acid } & A & 1.17 & 2.27 & 2.82 & 3.25 & 3.11 \\
\hline & B & 0.64 & 1.17 & 1.43 & 2.57 & 1.89 \\
\hline \multirow[t]{2}{*}{ 3-(3,4-dihydroxyphenyl)-2-propenoic acid } & A & 0.69 & 0.69 & 0.69 & 0.64 & 2.42 \\
\hline & $\mathrm{B}$ & 0.46 & 0.64 & 0.74 & 0.89 & 1.60 \\
\hline \multirow[t]{2}{*}{ 3,5-dimethoxy-4-hydroxybenzoic acid } & $A$ & 1.07 & 2.81 & 3.38 & 4.10 & 4.15 \\
\hline & B & 0.36 & 0.68 & 0.91 & 1.31 & 1.34 \\
\hline \multirow[t]{2}{*}{ 4-hydroxy-3-methoxybenzal dehyde } & A & 1.73 & 3.42 & 4.36 & 5.27 & 5.81 \\
\hline & $\mathrm{B}$ & 0.75 & 1.20 & 1.51 & 1.96 & 2.28 \\
\hline \multirow[t]{2}{*}{ 3,5-dimethoxy-4-hydroxybenzal dehyde } & A & 4.10 & 9.27 & 11.39 & 13.67 & 14.62 \\
\hline & $\mathrm{B}$ & 1.21 & 2.10 & 2.72 & 3.76 & 3.62 \\
\hline \multirow{2}{*}{ 3-(4-hydroxy-3-methoxyphenyl)-2-propenoic acid } & A & 0.26 & 0.38 & 0.43 & 0.50 & 0.36 \\
\hline & $\mathrm{B}$ & 0.23 & 0.32 & 0.37 & 0.51 & 0.36 \\
\hline \multirow[t]{2}{*}{ 4-hydroxy-3-methoxycinnamal dehyde } & A & 2.19 & 5.62 & 6.23 & 6.84 & 7.26 \\
\hline & B & 0.95 & 1.93 & 2.12 & 2.76 & 3.34 \\
\hline
\end{tabular}

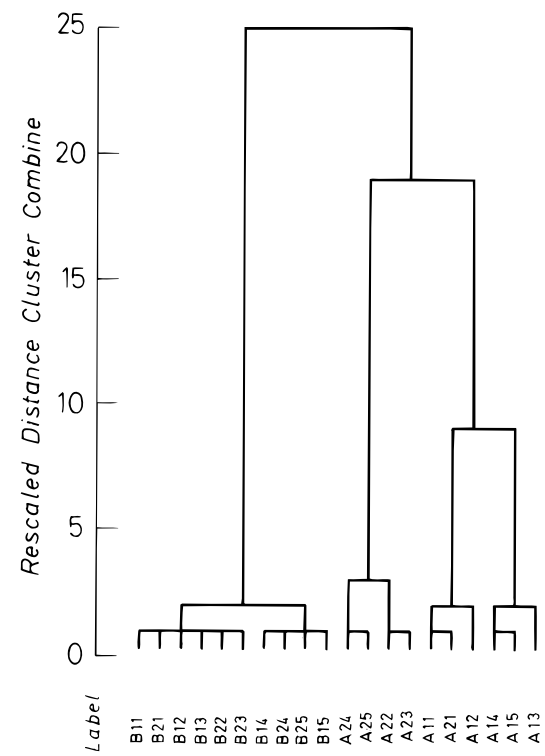

Figure 2. Dendogram: $A_{i j}$, spirit obtained from type $A$ cider; $B_{i j}$, spirit obtained from type $B$ cider; i, repetition number; $j$, aging step.

analysis. The aim of this multivariate technique is to search for 'natural' groupings among samples. In our case, a $20 \times 20$ matrix consisting of squared Euclidian distances, where each observation was represented by 12-dimensional vectors, was employed for hierarchical cluster analysis of the data, using the average linkage method. As we can see in the dendrogram (Figure 2), two clusters were found above 20.0 in the rescaled distance; the first cluster consisted of spi rits made from the type $B$ cider, while the second cluster included cider brandies obtained from traditional cider (type A). From the first cluster, two additional clusters occured below 5.0 in the rescaled distance, which included, on the one hand, the more aged spirits and, on the other hand, the less aged spirits, both obtained from type B cider; the cluster that initially grouped the distillates of type A cider was split into three clusters below $40 \%$ of the highest level of grouping, on the basis of the aging time of the spirits (Figure 2).
Factor Analysis of the Internal Structure. In order to ascertain if the data matrix might be considered adequate for factor analysis, different tests were carried out. Thus, it resulted that $62 \%$ of the correlations between variables were $>| \pm 0.5|, 89.4 \%$ of correlations being significant at the $5 \%$ level; the determinant of the correlation matrix was 0.0000 ; the Bartlett test of sphericity $\left(\chi^{2}=471.22\right)$ was significant at the $0.01 \%$ level; the Kaiser-Meyer-Olkin measure was 0.72617 ; and finally, an elevated number of measures of sampling adequacy above 0.7 were detected. Consequently, the data matrix could be considered appropiate for factor analysis.

The number of principal components $(\mathrm{PC})$ was determined from the correlation matrix, having previously standardized the data. Three PC values that accounted for $89.1 \%$ of the variance were chosen on the basis of Kaiser's criterion (eigenvalues higher than 1.0 are chosen). The percentage of variance of each variable explained by the two principal factors (communality) was greater than $81 \%$ for $66.7 \%$ of the variables studied.

In order to ascertain the latent structure of the data, a Varimax rotation was carried out. As can be seen in Figure 3 , where the variables are projected onto the plane formed by the two principal factors considered (total variance explained $79.8 \%$ ), the first eigenvector is closely related to 2-furancarboxal dehyde due to the high negative loading; however, 4-hydroxy-3-methoxycinnamal dehyde, 5-(hydroxymethyl)-2-furancarboxaldehyde, 4-hydroxybenzaldehyde, 3,5-dimethoxy-4-hydroxybenzaldehyde, 3,5-dimethoxy-4-hydroxybenzoic acid, and 4-hydroxy-3-methoxybenzaldehyde had high positive loadings for this varivector. On the other hand, 3,4dihidroxybenzoic acid, 4-hydroxy-3-methoxybenzoic acid, 3-(3,4-di hydroxyphenyl)-2-propenoic acid, 3-(4-hydroxy3-methoxyphenyl)-2-propenoic acid, and 3,4,5-trihydroxybenzoic acid are closely associated to the second varivector.

A projection of the observations onto the plane formed by the first two components is shown in Figure 4. As can be seen, the first component allows us to differentiate between the spirits manufactured from different cider types, A and B, while the second component is 


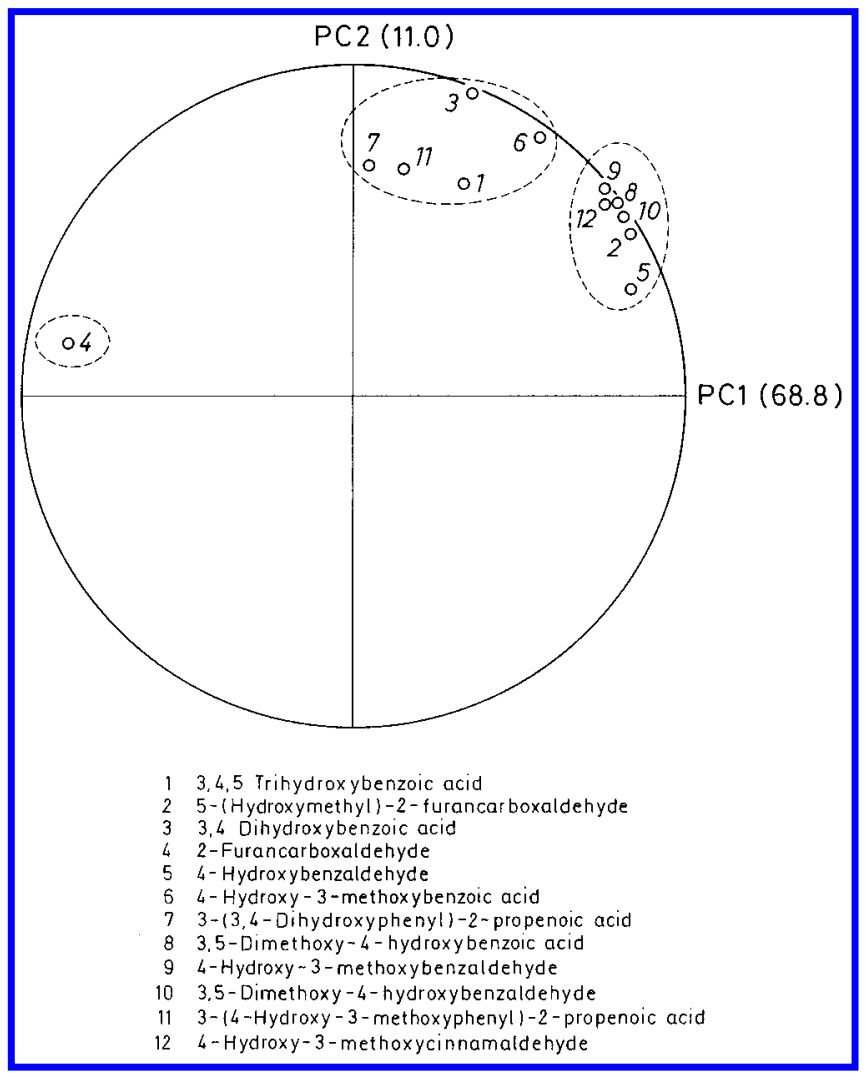

Figure 3. Two-factorial axes projection of variables.

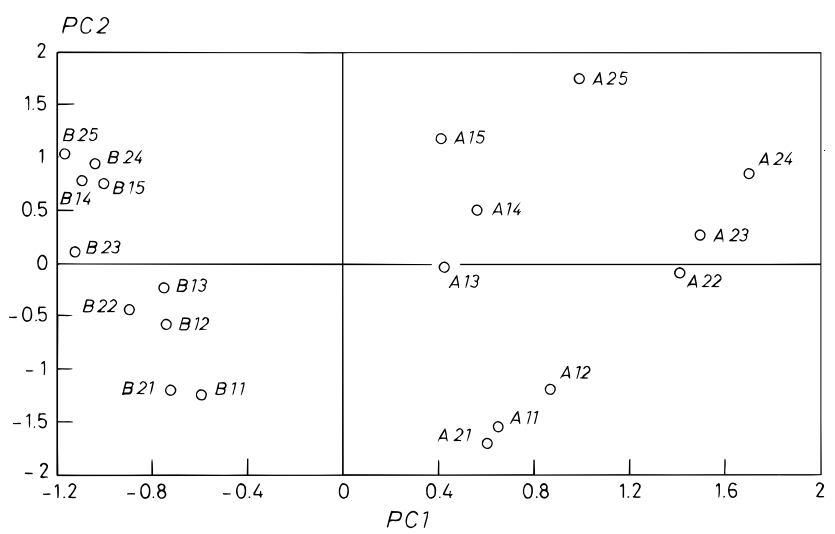

Figure 4. Eigenvector projection of spirits.

related to the aging time, especially when the distillates obtained from type B cider are considered. The scores for the first rotated component were higher in type $A$ than type $B$ spirits, and the spirits with more aging time usually had higher scores than the young spirits for the second rotated component (Figure 4). Consequently, the compounds associated with the first principal component may be employed for classifying the spirits on the basis of the raw material, and those related to the second principal component may be used for determining the degree of aging.

\section{LITERATURE CITED}

Baldwin, S.; Black, R. A.; Andreasen, A. A.; Adams, S. L. Aromatic congener formation in maturation of alcoholic distillates. $\perp$. Agric. Food Chem. 1967, 15, 381-385.
Delgado, T.; Gómez Cordovés, C.; Villarroya, B. Relationships between phenolic compounds of low molecular weight as indicators of the aging conditions and quality of brandies. Am. I. Enol. Vitic. 1990, 41, 342-345.

Lehtonen, M. High performance liquid chromatographic determination of nonvolatile phenolic compounds in matured distilled alcoholic beverages. 1 . Assoc. Off. Anal. Chem. 1983, 66, 71.

Miller, D. P.; Howell, G. S.; Michaelis, C. S.; Dickmann, D. I. The content of phenolic acid and aldehyde flavor components of white oak as affected by site and species. Am. I. Enol. Vitic. 1992, 43, 333-338.

Puech, J. L. Characteristics of oak wood and biochemical aspects of Armagnac aging. Am. I. Enol. Vitic. 1984, 35, 77-81.

Puech, J . L. Phenolic compounds in oak wood extracts used in the ageing of brandies. L. Sci. Food Agric. 1988, 42, 165172.

Puech, J . L.; J ouret, C.; Deibner, L.; Alibert, G. Phenolic compounds in Armagnac and Rum. II. Degradation products of lignine: aldehydes and aromatic acids. Ind. Alim. Agric. 1977, 483-493.

Puech, J. L.; Lepoutre, J. P.; Baumes, R.; Bayonove, C.; Moutounet, $M$. Influence of thermal treatment of barrels on the evolution of some oak components in spirits. Abstracts of Papers, 1st I nternational Scientific Symposi um of Cognac; Lavoisier-Tec \& Doc: Paris, 1992; p 583.

Quesada Granados, J .; Villalón Mir, M.; López García de la Serrana, H.; López Marínez, C. Comparison of spectrophotometric and chromatographic methods of determination of furanic aldehydes in wine distillates. Food Chem. 1995, 52, 203-208.

Salagoïty-Auguste, M. H.; Tricard, Ch.; Sudraud, P. Simultaneous determination of aromatic aldehydes and coumarins by high-performance liquid chromatography. A pplication to wines and brandies stored in oak barrels. $\perp$. Chromatogr. 1987, 392, 379-387.

SAS. ANOVA. In SAS/ STAT TM Guidefor Personal Computers; J oyner, S. P., Ed.; SAS Institute: Cary, NC, 1985; Chapter 12

SPSS. SPSS-X User's Guide; SPSS: Chicago, 1988.

Tricard, Ch.; Salagoity M. H.; Sudraud, P. Scopoletin: A marker of the maturing in oak barrels. Connais. Vigne Vin 1987, 21, 33-41.

Villalón Mir, M.; López García de la Serrana, H.; López Marínez, C.; Quesada Granados, J . The influence of oak on the furanic aldehyde contents of distillates subjected to aging. $L$. Liq. Chromatogr. 1991, 14, 3615-3621.

Villalón Mir, M.; Quesada Granados, J .; López García de la Serrana, H.; López Marínez, C. High performance liquid chromatography determination of furanic compounds in commercial brandies and caramels. L. Liq. Chromatogr. 1992, 15, 513-524.

Received for review November 28, 1995. Revised manuscript received J uly 12, 1996. Accepted J uly 16, 1996. ${ }^{\otimes}$ This work was financially supported by FICYT and the Principado de Asturias.

\section{J F950782T}

$\otimes$ Abstract published in Advance ACS Abstracts, September 1, 1996. 